EUROPEAN UNIVERSITY INSTITUTE, FLORENCE

DEPARTMENT OF POLITICAL AND SOCIAL SCIENCES

EUI Working Paper SPS No. 2004/12

School Achievement of Pupils from the Lower Strata in Public, Private Government-Dependent and Private Government-Independent Schools:

A Cross-National Test of the Coleman-Hoffer Thesis

RENSE CORTEN and JAAP DRONKERS

BADIA FIESOLANA, SAN DOMENICO (FI) 
All rights reserved.

No part of this paper may be reproduced in any form without permission of the author(s).

(C) 2004 Rense Corten and Jaap Dronkers

Published in Italy in October 2004

European University Institute

Badia Fiesolana

I - 50016 San Domenico (FI)

Italy

www.iue.it 


\title{
School achievement of pupils from the lower strata in public, private government-dependent and private government-independent schools: A cross-national test of the Coleman-Hoffer thesis
}

\author{
Rense Corten \& Jaap Dronkers ${ }^{1}$
}

\begin{abstract}
We consider the question whether pupils from the lower social strata perform better in private government-dependent schools than in public or private-independent schools, using the PISA 2000 data on European high schools. In the eighty's, Coleman and Hoffer (1987) found in the USA that the performance of these pupils was better at religious schools than at comparable public schools. Dronkers and Robert (2004) found in PISA-data for 19 OECD countries that private government-dependent schools are more effective then comparable public schools, when controlled for characteristics of pupils and parents and the social composition of the school. The main explanation appeared to be a better school climate in private schools. Private independent schools were less effective than comparable public schools, but only after controlling for the social composition of the school. As a follow-up we now investigate, again with the PISA-data of these 19 OECD countries, whether this positive effect of education in private governmentdependent schools differs between pupils from different strata. We use various indicators to measure social strata: social, cultural and economic. We expect that the thesis of Coleman \& Hoffer does hold for private government-dependent schools, because in these 19 OECD countries they are mostly religious schools, which have more opportunities to form functional communities and create social capital. But for private independent schools, which due to their commercial foundation are less often functional communities, this relation is not expected to hold. The results show that private government-dependent schools are indeed slightly more effective for pupils with less cultural capital, but that private independent schools are also more effective for pupils from large families or low status families.
\end{abstract}

\section{Introduction}

Within the field of school effectiveness research, the research on differences in effectiveness of different types of schools has taken a special position: probably few subjects within the sociology of education have created such controversies as the research on effectiveness of private and public schools. A subtopic of this discussion that may be even more controversial concerns questions about the effectiveness of private versus public schools for different groups of pupils, and especially pupils from the lower strata of society. A related question is whether private schools that exist alongside public schools can increase or decrease educational inequality with regard to social class. In the United States, the discussion on these so-called differential school effects is closely related to the rather intense "Parental Choice" policy debate, and virtually all of the research on this topic has concentrated on the American situation. In European countries the coexistence of private owned but public funded education with public education and fully private education is more common, but also in these countries there exist ongoing policy debates on for example the tensions between religious and public education and the consequences of educational segregation that are related to the effectiveness of different school types. This shows that the question of differential school effects should not be limited to the United States.

The cross-national PISA data that have recently become available allow us to address these questions in a broader international context. In this we build on the earlier study using the same data by Dronkers and Robert (2003) who examined differences in effectiveness between private and public schools. We now extend this research by asking whether private and public schools differ in their effects on pupils from the lower strata. 


\section{Public and private education}

Within the educational systems of Western industrial societies, schools can be roughly categorized on two dimensions. On one hand, the issue is who takes decisions concerning the organization and curricula that schools provide; on the other hand, who finances this education. In relation to the first issue, two types of schools have emerged in most western countries. As a result of the struggle between the state and the established church, states have taken on the responsibility of organizing education. Here lies the root of public education that is fully governed and financed by public agencies (Archer, 1984). At the same time however, for different reasons schools have been established by private initiatives, as a result of the efforts of churches and other religious institutions, but also of ideological or commercial organizations. Although this type of schools will often still have to comply with government regulations to a certain extend (partly also depending on the amount of financial support by the government, as will be discussed later), the crucial decisions regarding the school's affairs are made by private entities. Within the private sector, schools can again be classified as either government-dependent or government-independent by the extent to which they are subsidized by the state. Subsidizing of private schools by governments is in many countries secured by law, either in the constitution (The Netherlands, Germany) or in normal law (like in France for example). In many cases this right results from the claims of mostly religious groups to education based on the values and ideologies of the parents who are part of these groups, and who are considered to be responsible for the way their children are raised. Alongside these private government-dependent schools, there exist in a number of countries private schools that do not receive any government support, and that where mostly established for non-religious reasons by parents or organizations who have special pedagogical ideologies or societal aims. These schools finance themselves by means of pupil fees, donations, sponsoring and the like. As we said before, the two dimensions - governance and financing cannot be considered to completely independent: when the amount of financial support of private schools by governments becomes larger, these governments will also demand a higher degree of influence on the programs that the schools offer. But even schools that are completely independent financially will generally not be completely free to determine the contents of their programs, and will have to comply with minimal requirements on quality and safety. Moreover, the social context will also place constraints on school's freedom: for example diploma's that meet generally accepted standards have become indispensable in modern societies.

The different types of schools described here can be seen as being the result of two different approached to schooling. According to one point of view, schooling is an instrument of society as a whole (as represented by the central state) to prepare individuals for a life within society, independent of their social background, and in which religious convictions are considered to be a private matter. Public education results from this point of view. The competing standpoint states that schools are not just an instrument of society, but also of parents or the social and cultural groups to which they belong. The aim of schooling according to this point of view is to offer young people an education that is in accordance with the way of life of their parents and their environment. Private education is related to this approach (Coleman \& Hoffer 1987, Godwin \& Kemerer 2002).

\section{Differences in school effectiveness between school types}

A range of previous research shows that there are differences between the effectiveness of different types of schools: in many cases, the scholastic achievement of pupils appears to be higher at private dependent schools then at public schools. In an overview of European research, Dronkers (2004) concludes that this is the case in Belgium, France, Hungary, the Netherlands and Scotland, and to some lesser extend in Germany. In a recent cross national 
analysis using the PISA 2000 data, Dronkers and Robert (2003) also find that there are differences between the school types: while private government-dependent schools appear to be more effective then public schools, these are in turn more effective then private government-independent schools. These differences become less strong, but do not disappear when controlled for differences in pupil characteristics and the composition of the pupil population. In other, mostly American research comparable results are found (see for example Coleman, Kilgore \& Hoffer 1982, Coleman \& Hoffer 1987, Bryk, Lee \& Holland 1993).

For these results - that are not uncontroversial, see Sørensen \& Morgan, 2000 - several explanations have been provided in the literature. In the first place, differences in effectiveness between schools could be explained by differences in the characteristics of pupils. Because private schools are more likely to demand pupil fees, they are more likely to attract pupils from the higher social-economic strata, resulting in better scholastic achievement on average. Moreover, the composition of schools regarding the background characteristics of the pupils plays an independent role: schools that have a relatively high number of "good" pupils will build up a good academic reputation that will attract better teachers (and even more good pupils), and there will be less factors that disturb the educational process; it will for example be less necessary to repeat the same subject-matter over and over again then at schools that have a less favorable pupil composition. Second, it is possible that private schools can provide better learning circumstances, like a more extensive curriculum or more teachers per pupil. Third, differences related to school climate might explain differences in scholastic achievement between schools. Since in most countries public education is most standard, attending a private school will be the result of a deliberate choice made by the parents. It can be expected that the values and expectations of pupils at private schools will be more similar than those of pupils and teachers at public schools. This will in turn lead to a better school climate including types of behavior of both pupils and teachers that improve scholastic achievement.

The study by Dronkers and Robert (2003) shows that several of these factors play a role. Differences in background characteristics and school composition effectiveness between public and private schools appear to be able to account for a large part of the effectiveness differences between schools, and can even explain the difference between public schools and private independent schools fully. In fact, private independent schools even appear to be less effective then public schools, considering the favorable composition of their pupil population. Controlling for differences in learning conditions does not influence the remaining differences between public and private dependent schools; however it appears that differences in school climate can account for these remaining differences. For this reason Dronkers and Robert consider this factor the most important explanation of effectiveness differences between public and private government-dependent schools.

\section{The Coleman-Hoffer thesis: functional communities and social capital}

The school climate argument shows some resemblance to Coleman and Hoffer's main thesis in their study of American school careers. In the eighties they concluded not only that religious (mostly catholic) private schools were more effective for the average pupil, but also that it were the pupils from the lower social-economic strata that appeared to benefit most from private education. This finding (although not unchallenged - in a later study Hoffer (1998) did not find any such interaction effect) seems to contradict the commonly held presumption that it would be that public schools that offer the relatively better opportunities to pupils from low social classes. After all the public schools are supposed to provide a decent education to everyone, while private schools are focusing on specific subgroups of society.

The explanation for this effect according to the authors can be found in social capital. They distinguish between two types of communities as related to schools: functional communities 
and value communities. The members of functional communities constitute a structural system of social interaction: they encounter each other in different kinds of social situations en know each other personally. Functional communities display, in other words, a high level of network density. As a result, within functional communities there exists a high level of value consistency: there is a consensus on the values and expectations regarding (in this case) education. In contrast, value communities are communities which members (parents and teachers) share values and expectations regarding education, but that do not constitute functional communities: outside the school, there is no structural interaction or social network between the members.

According to Coleman and Hoffer, functional communities can be beneficent to their members because of the social capital they offer: because there is interaction between parents inside and outside the school, norms can be maintained that create a stable and positive school climate, improving the pupils' scholastic achievement. This school climate consists (among other things) of a sense of order, an atmosphere oriented at learning, and of a clear idea of what is expected of pupils, which implies a clear and focused curriculum.

This social capital provided by the school is different from the human capital (education and resources of the parents) and social capital (support of children in their educational career) that exists within families. While pupils with favorable backgrounds in this regard will learn the right behavior in their families and make the choices that favor scholastic achievement without help from school, pupils without such a background need the social capital that is provided by the school to develop the right behavior and to make the right choices. Most likely, those will be the pupils from the lower social strata. Thus social capital provided by the school is more often a necessary condition for school success to low class pupils, while it will at its best only a complement to the already available resources of the pupils from the higher social strata.

The differences between schools could now be explained by the differences in the social structures that surround different types of schools. Private government-dependent schools resemble the religious (Catholic) schools of Coleman and Hoffer's survey, where (at least a part of) the parents connected to the school would attend the same church. This constitutes the functional community in which such schools are embedded, that generate the social capital that - through a favourable school climate - especially improve the scholastic achievement of pupils from the lower social strata. Public schools and private independent schools, in contrast, will generally not be part of functional communities: the parents of pupils at these schools have chosen these schools for their own reasons but do not constitute communities outside the school, and therefore these schools lack the social capital that is able to maintain a favourable school climate.

This mechanism would thus explain why pupils from the lower strata perform relatively better at the (mostly religious) private dependent schools, which leads to our first hypothesis:

Hypothesis 1: Scholastic achievement of pupils from the lower social strata is better on private government-dependent schools then on public schools.

As said before, private government-independent schools are not expected to be embedded in functional communities. Therefore, we do not expect lower class pupils to perform relatively better on this type of schools. There is even reason to expect that private independent schools have less social capital on offer then public schools: because the choice for a privateindependent school will more often be a deliberate choice made by parents who live relatively far apart, these schools are less likely to attract pupils from the immediate surroundings then do public schools. For this reason, lower class pupils have more opportunities to benefit from 
social capital (caused by a local community) then do pupils at private independent schools. Hence our second hypothesis:

Hypothesis 2: Scholastic achievement of pupils from the lower social strata is less good on private government-independent schools then on public schools.

These two hypotheses, that proved to hold for American high schools in the eighties, will be tested from a more international perspective and with recent data in the following.

\section{Data}

In order to test the two hypotheses specified earlier we use the data from the PISA 2000 survey. In the PISA project, coordinated by the OECD, 15-year old pupils from 32 OECD countries are tested on skills and surveyed on their personal circumstances on a three year basis ( 2000 being the first time), while at the same time information is collected on schools by surveying superintendents.

The survey consists of a stratified two-step survey of schools with 15 year old pupils, in which all 15-year old pupils and the superintendents of the selected schools are interviewed. The data files and SPSS syntax files including the full answers of all individual pupils and superintendents are available from the OECD website ${ }^{2}$. We have combined these data files into one file. In addition to the original variables the PISA researchers have created a number of aggregate indicators, based on the answers of pupils and superintendents. Information on these indices and their reliability can be found in the Manual for PISA 2000 Database and the PISA 2000 Technical Report, both available from the OECD webpage. We chose to use these generally accepted indicators in or analyses, rather then to develop our own indicators.

The use of these data has some important advantages. In the first place, the questionnaire (including the test) that was used was fully standardized, which makes the data comparable between the different schools and countries. This allows for abstraction from specific national context, yielding a better and test of the hypotheses that can be more easily generalized. Earlier research on school effects was mostly limited to the national context of a single country, and in the case of differential effects this country was almost exclusively the United States. A second advantage is that cross-national data produce a larger variance in school characteristics, which allows for better control for relevant school characteristics then would have been possible with data on a single educational system.

One important disadvantage of the PISA 2000 database is its cross-sectional nature: the measurement of the pupil's abilities resembles a "snapshot" of their situation at the time. We know nothing about their further development, nor of their previous experiences and achievement in education. It is generally assumed that a longitudinal measure of educational results with regard to school characteristics is superior to cross-sectional observation, because longitudinal data allow for better control of unmeasured characteristics and (self)selection. Unfortunately, longitudinal cross-national data are not available at this moment and are not likely to become available in the next future. Moreover, we know from the history of effective schools research that although the effectiveness of non-public schools is usually lower in longitudinal research then in cross-sectional research, the direction of the results is the same in both types of data (compare for example the results of Coleman, Hoffer and Kilgore (1982) to the longitudinal results of Coleman and Hoffer (1987)). Therefore, we think that an analysis of these exceptional cross-sectional data is interesting from a scientific point of view. We use in this paper the same data and variables as used by Dronkers and Robert (2003). 


\section{School \& Countries}

The PISA data distinguishes between different types of schools in a way that resembles our distinction as described earlier. The schools are classified as either public or private solely according to whether a public agency or a private entity has the ultimate power to make decisions concerning the institution's affairs. An institution is classified as public if it is (1) controlled and managed directly by a public education authority or agency or, (2) is controlled and managed either by a government agency directly or by a governing body (Council, Committee etc.), most of whose members are appointed by a public authority or elected by public franchise. In contrast, an institution is classified as private if it is controlled and managed by a nongovernmental organization (for example a Church, Trade Union or business enterprise), or if its Governing Board consists mostly of members not selected by a public agency. The terms "government-dependent" and "independent" refer only to the degree of a private school's dependence on funding from government sources; they do not refer to the degree of government direction or regulation. A government-dependent private school is one that receives more than 50 per cent of its core funding from government agencies. An independent private school is one that receives less than 50 per cent of its core funding from government agencies. "Core funding" refers to the funds that support the basic educational services of the schools. It does not include funds provided specifically for research projects, payments for services purchased or contracted by private organizations, or fees and subsidies received for ancillary services, such as lodging and meals.

The countries we have selected are, in alphabetical order, Austria, Belgium, the Czech Republic, Denmark, Finland, France, Germany, Hungary, Ireland, Italy, Netherlands, New Zealand, Poland, Portugal, Spain, Sweden, Switzerland, United Kingdom, and the USA. These countries have enough absolute numbers of pupils attending a form of private school in the PISA data for reliable estimates of effectiveness to be made (see table 2 of Dronkers \& Robert, 2003). We have restricted ourselves in this analysis to those indicators of social background that were significant in earlier analyses. Moreover we don't use those indicators that refer to behavior of parents and pupils, because it might be possible that they are a consequence of scholastic results, in stead of the cause or effect of (self)selection. The use of these variables might flaw the conclusions on the causal relations between these variables (Dronkers \& Robert, 2004; Sørensen \& Morgan, 2000).

\section{Data preparation}

We use the unweighted data, because we are interested in the 'quasi-experimental' effect that being a pupil in a private or public school has on educational results. From this perspective, each country is an 'experimental' case, which should not be reweighed because of its population size. Such a reweighing with real pupil population sizes for each country would produce an unbalanced result, in which countries with the highest pupil populations (and thus with certain types of public and private schools) would dominate the results, while countries with small pupil populations (and thus with certain types of public and private schools) would have a lesser effect on the outcomes. An analysis with reweighed data would, therefore, produce invalid estimates of the effectiveness of the various public and private schools. For this reason, the analysis sticks to the original number of cases, with some corrections for very small schools (see below). Fortunately, the sample-size in the various countries did not vary too much, allowing us to treat countries under more or less equal 'experimental' conditions, and without deleting cases.

In addition to the selection of countries, we also follow a selection procedure with respect to schools and pupils, and include only those pupils for whom the basic information on gender, school grade, valid score of achievement (the dependent variables), on type of 
school as described above, location of school, and family type was available. In the case of the other independent variables, if missing cases occurred in the data, these were replaced by the mean value of the variable. We deleted also all schools with less than 11 pupils who participated in the study, because too many schools with very low numbers of pupils could jeopardize the reliable estimation of the effectiveness of these schools. The PISA data had a large number of schools with only a few participating pupils, because of its aim to measure a representative sample of all 15 year old pupils. In order to include retarded 15 year old pupils at lower grades or advanced 15 year old pupils at higher-grades, schools with these retarded or advanced pupils were added by PISA to the sample. This procedure produced a relatively large number of schools with very low numbers of 15 years old pupils, which we deleted from our analyses. This necessary deletion may lead to a bias towards sectors with larger schools, but we prefer this bias to unstable or unreliable estimates of school effects.

\section{Dependent variables.}

For this analysis, we decided to use two of the three possible dependent variables on pupils' performance. The survey contained measures on pupils' reading, mathematics and science abilities; we will use the reading and the mathematics scales as dependent variables in the analysis in order to have one measure which is of a more cultural character, and one measure which is of a more cognitive character. The reading scale gives information on the reading proficiency of pupils, which is based on retrieving information from text, interpreting text, and reflecting on a text or evaluating it, based on numerous tasks. The mathematics scale aims to measure the ability of pupils with respect to interpreting and translating problems into a mathematical context, using mathematical knowledge to solve problems, and interpreting and communicating their results, again based on various tasks. Both performance measures were constructed by applying weighted maximum likelihood estimates (see Warm 1985) and were translated into scales with a mean of 500 and a standard deviation of 100 . In addition, the PISA file contains measurement error variables for both the reading ability and for the mathematics ability estimations. We will include these error term variables in our analysis to control for the possible measurement error of the performance variables. Given this possibility to correct measurement error, we decided not to combine the dependent variables into one scholastic achievement indicator. Indeed, loosing this possibility for correcting measurement error is an important argument against a combination of the dependent variables.

\section{Sociological and demographic characteristics of pupils and parents.}

Most of the independent variables used to predict pupils' achievement are combined indices, developed by PISA. These were also constructed by applying weighted maximum likelihood estimates (see Warm 1985) and were standardized in such a way as to have a mean of 0 and a standard deviation of 1 at the international level of all countries. The first set of independent variables involves pupils' as well as their parents' social and demographic characteristics. We will differentiate between males and females in the analysis. Despite a slight variation, we will control for school grade and age (measured in months in the data). ${ }^{3}$ In keeping with established traditions of social mobility and status attainment research, we will include fathers' and mothers' occupation and education as indicators of social origin. Occupation is measured in the data by the international socio-economic index (ISEI) (Ganzeboom et al. 1992), while education is measured by the ISCED scale (OECD 1999). Further information on family background is number of siblings, as well as family structure which distinguishes between nuclear families, single parent families and other family constructions (for a separate analysis of the different effects of various family forms on scholastic results in these 19 OECD countries, see Garib, Martin \& Dronkers, 2003). The cultural climate of the family is 
expected to be an important factor of pupils' performance. In this regard, the PISA survey provides information on how frequently parents discuss political and social issues, books, films, and television-programs with their offspring. PISA has combined these individual items into an index labeled Parents' academic interest. The PISA index on Family cultural possession is based on having classical literature, books of poetry, works of art at home. In addition to cultural possessions, financial capital can also be of importance for educational outcomes. As a direct measure of parental income is quite unreliable given that it is the pupils in the school who report on it, a Family wealth index has been constructed based on the presence of dishwasher, television, cellular phone, motor car, computer, and a link to the internet at home. Since the research aims to explore the predictors of pupils' performance, we need to control for pupils' educational circumstances at home.

\section{School composition.}

Since the intention of this analysis is to compare pupils' performance in different kind of public and private schools, we must control for the social composition of the school population in order to avoid biased measuring in evaluating the effectiveness of these types of schools. In order to achieve this goal, we compute three aggregated variables from individual pupils' characteristics: the school average of father's occupational status (ISEI), the school average of family's wealth and the school average of parents' academic interest. These three aggregated indices of school compositions cover the three most important dimensions of inequality in school composition (financial; occupation; cultural). Adding more aggregated indices does not change our results. The next indicator of school composition is the proportion of girls in the school. Finally a series of variables indicates the place of residence for the pupil ranging from small settlements (inhabitants less than 3000) up to capital city, is included in the analysis.

\section{Teaching and learning conditions.}

Indicators for the teaching and learning conditions in schools are also considered as variables in the analysis of differences in effectiveness. The first simple indicator measure the time in terms of number of minutes spent each week at school reading and in mathematics classes by the pupil. This information is given by the pupil. The other information on teaching and learning conditions was provided by school principals. The first indicator is school size, measured by the number of pupils in the school. Principals were also asked to report on the number of teaching weeks per year, the number of class periods per week, and the number of teaching minutes per class; the variable Hours of schooling per year summarizes this information. The availability of "human capital" in the school is another factor which may affect pupils' performance. We use two "rough" indicators to measure conditions in the school in this respect, and this is the School size (number of pupils) and pupil/teacher ratio, where the total number of pupils is divided by the total number of teachers in the school. The Schools' instructional resources score is based on the principals' reports on the availability or lack of teaching materials, multi-media resources, science laboratory equipment and facilities for fine art education.

\section{School climate.}

School climate represents a final set of school related variables which can influence pupil performance and thus explain differences in effectiveness. The PISA survey asked school principals to express their general perceptions of both teacher-related and pupil-related factors affecting the school climate. Teacher related factors include high or low expectations of the teachers towards their pupils, teacher absenteeism, frequency of changes in the teaching staff, teachers' encouragement of pupils to achieve better, or strictness with the pupils. Pupil related 
factors include pupil absenteeism, disruption of or skipping of classes, lack of respect for teachers, use of alcohol or drugs, and the intimidation of other pupils. These indicators are combined into two indices labeled Teacher misbehavior and Pupil misbehavior. Finally, the Teacher morale index expresses principals' perceptions of teachers' morale, enthusiasm, on how much they take pride in the school and how much they value academic achievement.

\section{Method}

For the analysis of the data we use multilevel analysis (MlwiN 1.1, Rabash et al. 2000), which is generally considered as the best method to asses school effect differences (Scheerens \& Bosker, 1997) because this method is most able to handle the nested structure of the data. As a result of the use of the standard error at the individual level to correct for the use of partial test we have an analysis with four levels: the sub-individual level with the test scores on either reading or math as independent variables, the individual level with characteristics of pupils and parents as control variables, the school level with school composition, school type and other school characteristics as explanatory variables, and the country level with no specific variables.

The plan of the analyses is as follows. We start with a basic model (1) that includes the test score for the reading or mathematics test as the dependent variable, and background characteristics of pupils and parents as independent variables, as well as school type. In the second step we ask whether the effects of social background vary on the school level; a significant variance of these variables on the school level would suggest an interaction between school characteristics and individual characteristics. The next step is to check whether the variance of background variables (if any) can be related to school type, by constructing and adding interaction variables with those background variables and school type. Model 2 then contains the interaction variables that proved to be significant, in addition to the variables of model 1 . We expand the model further by adding school level variables of social composition and school location (model 3), teaching and learning conditions (model 4) and eventually school climate (model 5). We conclude the analyses with a short note on a possible extension of the analyses. We try to avoid too many descriptive results, except for the most important variables. Readers interested in more extensive descriptions of the data are referred to Dronkers and Robert (2003).

\section{Results}

\section{Descriptive analysis}

Table 1 gives the averages of the dependent and the most important independent variables, separately per school type. The differences in the averages between public and private schools are clear and significant. Pupils on private independent schools have higher scores on language and mathematics, but have also a better social background (higher educated parents; higher parental occupational status; more parental academic interest; more cultural passions; higher family wealth). This is also true for pupils of private government-dependent schools, but their differences with pupils at public schools are smaller. Moreover, pupils of private government-dependent schools are lower on two points than pupils from other schools: parental academic interest and cultural possessions. The school composition of the private independent schools is far better that that of the public schools on the three indicators: average occupational status of fathers; average material wealth of families; average cultural possessions. For private government-dependent schools this is mainly the case for average occupational status, but the average cultural possessions by the families is lower. The hours of schooling per year are higher in private schools than in public schools, but the teaching conditions on private schools are not always more favorable than on public schools. The pupil/staff ration and the amount of instructional resources are worse on private schools 
compared to public ones. Finally is the level of misbehavior of teachers and pupils on private schools lower than on public schools and the teacher morale higher.

Public and private schools differ on an important number of aspects and any conclusion based on table 1 is impropriate and misleading. But it is also clear that private independent and private government-dependent schools also differ on a number of points and that it is therefore wrong to tread them as one homogonous group.

\section{Multi-level analyses}

Model 1: effects of school type and social background

The first columns of tables $2 \mathrm{a}$ and $2 \mathrm{~b}$ show the starting model with school type (public schools are the reference category) and the social background variables as independent variables. The positive effects of the dichotomous variables private independent and private government-dependent schools show that pupils on these schools do better in mathematics and reading than pupils of public schools with a comparable social background. This is especially true for pupils at private independent schools. The variables of social background have nearly all an effect in the same direction: a better social background improves the scholastic achievement on comparable school types. The only exemption is the variable 'family wealth', which has no significant effect on the mathematic score (the standard error is lager than the half of the coefficient) and has even a negative effect on the score of the reading test. This suggests that family wealth has at the most an effect via other social background variables. Finally the tables show the variances of the dependent variables at the individual level, the school level and the country level. The largest variance is at the individual level, followed by the school level and the country level.

\section{Random coefficients}

Multi-level analysis allows for investigating whether the effect of an independent variable of a lower level varies significantly between units of a higher level; in this case whether the effects of variables of the individual level (social background) vary between schools. Variance in the effects of social background variables might indicate an interaction-effect between social background and school characteristics. Tables $3 \mathrm{a}$ and $3 \mathrm{~b}$ show for each of the social background variables the 'fixed coefficient' (that is the average effect over all schools) and the variance in this effect ('random coefficient') between schools. The random effects are always separately estimated, using model 1 .

In the model with mathematics as dependent variable the effects of fathers' occupational status, fathers' educational level, the number of siblings, family wealth, cultural possessions and other family form are significantly different between schools. For reading all social background variables, except family form "single parent", do have significant variances at the school level. Therefore for these variables it is worthwhile to see whether these differences in effect between schools are related with school type (public, private independent; private government-dependent).

\section{Model 2: Interaction-effects}

In order to investigate whether the differences in effects of social background variables can be explained by the distinction between the three school types, we construct the interaction effects between those social background variables, which have a significant variance at the school level and the dichotomous school type variables. We estimate these interaction effects by adding them separately (two per social background variable) to model 1 . To save space we refer to these analyses to the tables Ala and A1b in the appendix and we continue here with the discussion of model 2, which is model 1 with all significant interaction effect included. 
The effects of cultural possessions and fathers' occupational status are significantly different between the three school types for mathematics. In order to ease the interpretations of these effects, we have centered the variables fathers' occupational status (for mathematics) and the number of sibling (for reading) on their averages (this was already done for cultural possessions; see section 'sociological and demographic characteristics of pupils and parents). As the consequence of this centration the main effects of private independent and private government-dependent schools now indicate the effects of these school types for the pupil with the average family cultural possession, with an average number of siblings and with a father with an average occupational status. The main-effects of cultural possession, fathers' occupational status and number of siblings now indicate the effects for pupils at public schools.

The interaction-effect of cultural possession on private independent is negative, which means that pupils with few cultural possessions in their families have higher scores on mathematics in private dependent schools than on a public school: that is few cultural possessions are a less important disadvantage at private dependent school. This confirms hypothesis 1 . For pupils on public schools the effect of cultural possessions is 5,0; for pupils on private independent school it is $2,7(=5,0-2,3)$. The interaction-effect between private independent and cultural possession is positive but just not significant: the effect of cultural possession is not significantly larger on private independent schools than on public schools.

The effect of fathers' occupational status differs between private independent and public schools, but not between the latter and private government-dependent schools. The interaction-effect between fathers' occupational status and private independent is negative, and also a little larger than the positive main effect. This means that the effect of fathers' occupational status is positive on public and private government-dependent schools $(0,367)$, but nearly zero and even slightly negative on private independent schools $(0,367-0,378=$ $0,011)$, in contradiction with hypothesis 2 .

The result that the interaction-effects between the other social background variables and school type are not significant, means that the effects of these background variables differ significantly between schools but not between the tree school types we are interested in right now. These differences might be explained by other school characteristics.

If we take reading as dependent variable, significant interaction-effects exist between school type and cultural possession, and with number of siblings. Just like with mathematics, there is a negative interaction-effect between cultural possessions and private governmentdependent schools (pupils with few cultural possessions in their families do better on private government-dependent schools than on public schools, corresponding with hypothesis 1), and its strength has about the same magnitude. There is again a positive interaction effect with private independent, although smaller and also not significant.

In contradiction to the model with mathematics as dependent variable, not fathers' occupational status but number of siblings has a significant interaction-effect with private independent schools. This interaction-effect is positive and larger than the main effect: while the effect of more siblings is negative on public schools, it is positive on private independent schools: pupils with more siblings do relatively better on the latter schools. This contradicts hypothesis 2 . The interaction-effect with private government-dependent is positive but not significant: private government-dependent schools don't differ from public schools in their effect of the number of siblings.

Finally the tables also show the variance per level and the variance in the main effects of the social background variables on the school level. If we compare this variance of the effects on the school level with that of table 3, we see that for mathematics the variance of the effect of cultural possession declines strongly (from 19,6 to 13,8), while that of the effect of fathers' occupational status only decrease slightly (from 17,6 to 16,5). Also for reading the 
variance of the effect of cultural possession becomes clearly smaller, but that of number of siblings decreases less. This shows that the differences in effects between schools can only be attributed partly to school type. There remains in all cases still some significant variance at the school level: there are obliviously still differences between schools regarding the effects of social background, which are not related with school type.

\section{Model 3: school composition and urbanization level}

In this and the next sections we try to explain the found significant interaction-effects between social background and school type by adding other school characteristics to model 2 . If the interaction-effects become smaller by this addition or even become insignificant, they can be explained by these school characteristics, but not or less by school type. In model 3 we start with this procedure by controlling for the various aspects of social and gender school composition and for the urbanization level of the municipality of the school. All additional variables in this model 3 are thus variables at the school level. In order to keep the results from various models easily comparable and because our hypotheses refer to the interactions between school types, we maintain also the insignificant interaction-effects from model 2 in the following models.

Tables $2 \mathrm{a}$ and $2 \mathrm{~b}$ show that school composition, especially the cultural aspect of social background, has strong effects on scholastic achievement. Also a lower urbanization level improves these achievements, and in the case of reading the percentage female pupils does the same. The main effect of private independent school becomes negative, which means that given the (good) social composition of these private independent schools, pupils of these schools achieve less relatively. The main effect of private independent is in both cases no longer significant.

With regard to the interaction-effects, their magnitudes are hardly changed by controlling for school composition and urbanization level, and in most cases become even slightly larger: thus the interaction-effects cannot be explained by school composition or urbanization level. It is however useful to discuss the relation between main effects and interaction-effects. Although the effect of private independent for mathematics is negative for the average pupil, the negative interaction-effect with fathers' occupational status makes that the effect of this school type becomes slightly positive for pupils with a father with a very low occupational status. But the positive effect of fathers' occupational status on public and private government-dependent schools is negative on private independent schools. For reading, the positive interaction-effect of the number of siblings has comparable consequences: for more than two siblings the effect of private independent becomes positive, because the negative effect of number of siblings becomes slightly positive at private independent schools.

It also becomes clear that, although the positive effect of private governmentdependent is not longer significant in both dependent variables, there is still a significant interaction-effect with cultural possessions: private government-dependent schools are not better or worse for the average pupil, but they are relatively better for pupils with few cultural possessions in their families and worse for those with many cultural possessions. Finally, we see that, for both dependent variables, the variance at the school level has strongly declined compared to the previous models without school composition. This suggests that these school characteristics are for a large part responsible for the differences in scholastic achievement between schools. The variance of the three social background variables at the school level is hardly changed compared with the previous models. 


\section{Model 4: teaching and learning conditions}

While in the previous sections we have focused on the pupils' characteristics, the analyses with model 4 are extended by characteristics of the teaching processes in schools. Nearly all additional variables of this model are variables measured at the school level, with the number of minutes spent each week at school reading and in mathematics classes by the pupil (learning time). For mathematics learning time and school size have a positive effect on achievement, while the pupil/staff ratio and (remarkably) the amount of schools' instructional resources have a negative effect. The total number of schooling per year has no significant effect. For reading only the pupil/staff ratio and the amount of schools' instructional resources have significant effects, in the same direction as for mathematics. Although these conditions for teaching and learning clearly have effects on scholastic achievement, there is hardly any change in the magnitude or direction of the interaction-effects. Also the main effects are almost the same as in model 3, just as the variance of these effects. Therefore, the interactioneffects between social background and school type cannot be explained by these school characteristics. The non-existence of a substantial decline of the variance at school level of the effects of cultural possession, fathers' occupational status and number of siblings confirms this conclusion.

\section{Model 5: school climate}

In the last extension of our analyses we add the characteristics of the school climate: the degree of misbehavior of teachers and pupils and the teachers' morale. The thesis of Coleman and Hoffer assumes that the relatively better scholastic achievement of lower social class pupils at private government-dependent schools is (among other things) caused by the functional community around these schools which make it possible to maintain a better school climate.

The last columns of tables $2 \mathrm{a}$ and $2 \mathrm{~b}$ show that specially the degree of misbehavior by the pupils has a negative effect on scholastic achievement (the same magnitude for both independent variables), while the teachers' morale has a small but significant and positive effect. Remarkably teachers' misbehavior has a positive effect on both dependent variables. But again we don't see any change for the interaction-effects or the variance in the effects of social background. Thus also differences in school climate cannot explain the difference of the effects of social background variables between the three school types. However there is some further decline of the main effect of private government-dependent school for mathematics, which was already no longer significant in the previous model.

\section{Additional analyses: interactions with composition variables}

In this section we discuss briefly a related possible explanation of the found significant interaction-effects between social background and school type: The possibility that the differences in the effect of social background is caused by an effect of school composition on the effect of social background on scholastic achievement. Differences in the effects of social background per school type could be explained by differences between schools in relation to the effects of school composition on the effect of social background. In the latter case it is the combinations between pupils' characteristics and school composition, and not the three school types, which produce the differences in effectiveness between public and private schools. In order to test this alternative hypothesis, we add to model 5 interaction-effects between the relevant aspect of social background (cultural possession, fathers' occupational status, number of siblings) and the school averages on these variables. From these analyses, for which we refer to the appendix, it is clear that only for reading the interaction-effect between number of sibling and private government-dependent school becomes slightly smaller (one point); in the other interaction-effects nothing changed by this addition. Also this alternative hypothesis on 
interactions between background and school composition cannot explain the differences of the effect of social background between the three school types.

\section{Conclusions and discussion}

We have found some, though modest, support for the first hypothesis that states that private government-dependent schools are relatively more effective for pupils from the lower social strata. Private dependent schools appear to be somewhat more effective for pupils with little cultural capital (as measured by the cultural possessions of their parents), even after controlling for differences in school composition, learning conditions and school climate. Moreover, it appears that this interaction effect can account for the higher effectiveness of private independent schools as found by Dronkers and Robert: private dependent schools are not more effective for the average pupil, but only for those with little cultural capital.

A few points must be noted however. In the first place the interaction effect we found is, although statistically significant, not very large, especially when compared with the effects that for example school composition on background variables has on school achievement. Second, we found a higher effectiveness of private dependent schools for pupils from the lower strata for only one out of ten available measures of social background. We think however that it is at least justified to state that if there are any differential school effects, those will not be in favor of the public schools.

In contrast to the first hypothesis, the second hypothesis, stating that the performance of lower class pupils would be worse on private independent schools, can clearly be regarded as refuted. Both aspects of social background that appear to have different effects on private independent schools as compared to public schools (father's occupational status for math and the number of siblings for reading) do so in the opposite direction: pupils that score low on these two measures for social background appear to perform better on private independent schools. But again it must be stressed that these effects are rather small, and only exist for one out of ten indicators for social background (per dependent variable). Moreover, while in the case of private government-dependent schools the interaction effect of cultural capital was consistent between the mathematics and reading test scores, in this case the interaction effects involve different variables for the two test scores.

With some moderate support for the first hypothesis and a clear refutation of the second hypothesis it seems hard to defend Coleman and Hoffer's theory of differential school effects and social capital. Moreover, the fact that differences in school climate do not help to explain the apparent differential effects does not favor their theory: school climate was supposed to act as an intermediate variable between the existence of a functional community and better school achievement of low social class pupils. This means that while there is evidence that some effects predicted by the theory do indeed occur, the mechanisms that are supposed to be responsible for these effects could not be identified.

We should however point out that our test of the Coleman-Hoffer thesis has in some respects been rather indirect. The original theory, for one thing, aimed at explaining differences between catholic schools and public schools, while we extended it's predictions to involve private-dependent schools in general (because the PISA data do not include a measure for religious affiliation of the school). Moreover the number of indicators with regard to the mechanisms of functional communities was limited to three (the measure for school climate). A defense of the theory in this fashion could state that the differential effects we found could be explained be other, now unmeasured characteristics of functional communities like a stricter and more focused curriculum. 
It is not so easy to come up with an explanation for the higher effectiveness of private independent schools for pupils from the lower strata, given that it is not school composition or teaching conditions. A possible cause of the positive effect of the number of siblings at private independent schools could be that family size is an ambiguous indicator of socialeconomic class. If upper class or very religious families have more children then the average family, the high achievements of the children from these families on private independent schools might explain the effects found. Another explanation might be that, given the better school climate on private independent schools as compared to public schools, these schools do in fact manage to constitute features of functional communities that public schools may be lacking (although the effects of these functional communities should be operating by other means then school climate in that case). This explanation would not only apply to the interaction effect of the number of siblings, but also to the effect of father's occupational status. Perhaps the local embeddedness of public schools, that was supposed to create functional communities, is not as strong as we assumed, and is the integrating effect of deliberate school choice on private independent schools more important in this regard. Also, the category of private independent schools might also be including some religious schools, which provides another reason to wish for a measure of religiousness in future surveys. A third explanation might be that we did not control for learning capabilities, insofar as they are not related to social origin. It is very well possible that low status families will only send their children to private independent schools if these children appear to be especially capable, for example with the support of grants that are specially designed by the private schools for this purpose. Many private independent schools offer some kind of grants or bursaries to scholastically very well performing children who cannot afford to pay their fees, in order to increase the intellectual level of their pupils and to legitimize their elitist function. It should however be remembered that although low status children tend to perform relatively better in private independent schools, the majority of low status pupils will not be able to access these schools in the first place because of the higher probability of extra fees.

The fact that some aspects of social background appear to be a smaller handicap at private schools means that schools of this type could, ceteris paribus, reduce educational inequality between social classes. In practice however, the high degree of (self-)selection of pupils of favorable backgrounds will in combination with the positive effects of school composition lead to a net increase in educational inequality as related to social class. The findings also indicate that statements in debates related to public versus private education should be carefully argued, especially if related to the emancipatory value of private schools.

\section{Literature}

Archer, M. S. (1984) Social origins of educational systems. London / Beverly Hills: Sage

Bourdieu, P. (1983). The Forms of Capital. In J. Richardson (ed.), Handbook of Theory and Research for the Sociology of Education. New York: Greenwood Press.

Bryk, A. S., Lee, V. E. \& Holland, P. B. (1993). Catholic schools and the common good. Cambridge (Mass.)/ London: Harvard University Press.

Coleman, J. S., Hoffer, T. B. \& Kilgore, S. (1982). High school achievement: Public, Catholic, and other private schools compared. New York: Basic Books.

Coleman, J. S. \& Hoffer, T. (1987). Public and private high schools. The impact of communities. New York: Basic Books.

Dronkers J. (2004) Do Public and Religious Schools Really Differ? Assessing the European Evidence. In Patrick J. Wolf \& Stephen Macedo (eds.) Educating Citizens: International Perspectives on Civic Values and School Choice. Washington D.C.: Brookings Institution Press (in druk). 
Dronkers, J. \& Robert, P. (2003). The effectiveness of public and private schools from a comparative perspective. San Domenico di Fiesole (Fi): European University Institute. EUI working paper SPS 2003/13 (http://www.iue.it/PUB/sps2003-13.pdf).

Ganzeboom, H. B. G., Graaf, P. de, Treiman, D. J. \& De Leeuw, J. (1992). A standard international socio-economic index of occupational status. Social Science Research, 21, 1-56.

Garib, G. Martin Garcia, T. \& Dronkers, J. (2003). Are the effects of different familyforms on children's educational performance related to the demographic characteristics and family policies of modern societies? Paper at the second conference of the European network for empirical and comparative research on the sociological aspects of divorce, Tilburg (Netherlands), November 13-16, 2003. http://www.iue.it/Personal/Dronkers/English/divorcePISA.pdf

Godwin, R. K. \& Kemerer, F. R. (2002). School Choice Tradeoffs. Liberty, Equity, and Diversity. Austin: University of Texas Press.

Hoffer, T.B. (1998). Social Background and Achievement in Public and Catholic High Schools. Social Psychology of Education 2, 7-23.

Hox, J. (2002). Multivariate Analysis. Techniques and Applications. Mahwah (NJ)/ London: Lawrence Erlbaum.

OECD (1999). Classifying educational programmes. Manual for ISCED97 implementation for OECD countries. Paris: OECD.

Rasbash, J., Browne, W., Goldstein, H., Yang, M., Plewis, I., Healy, M., Woodhouse, G., Draper, D., Langford, I. \& Lewis, T. (2000). A user's guide to MLwiN 1.1. London: Institute of Education, University of London.

Sammons, P., Hillman, J. \& Mortimore, P. (1995). Key characteristics of effective schools: A review of school effectiveness research. London: Office for Standards in Education and Institute of Education.

Scheerens, J. \& Bosker, R. (1997). The Foundations of Educational Effectiveness. Kidlington/New York/Toyko: Pergamon.

Sørensen, A., Morgan, S.L. (2000). School Effects: Theoretical and Methodological Issues. In Maureen T. Hallinan (red.) Handbook of the Sociology of Education. New York: Kluwer Academic/Plenum publishers.

Teddlie, C. \& Reynolds, D. (2000). The international handbook of school effectiveness research. London: Falmer. 
Table 1: Means and standard deviations of the dependent and the most important independent variables per school type.

\begin{tabular}{|l|l|l|l|l|}
\hline School type & $\begin{array}{l}\text { Private } \\
\text { independent }\end{array}$ & $\begin{array}{l}\text { Private } \\
\text { government- } \\
\text { dependent }\end{array}$ & Public & Total \\
\hline Reading & $553,5^{*}(91,7) \$$ & $529,9^{*}(94,0) \$$ & $504,3(99,9)$ & $509,7(99,5)$ \\
\hline Mathematics & $546,5^{*}(92,4)$ & $528,0^{*}(92,7) \$$ & $503,8(96,2)$ & $508,8(96,2)$ \\
\hline Fathers occupational status & $54,9^{*}(17,3) \$$ & $45,9^{*}(16,3) \$$ & $43,6(15,4)$ & $44,3(15,7)$ \\
\hline Fathers educational level & $5,0^{*}(1,2) \$$ & $4,5^{*}(1,4) \$$ & $4,3(1,3)$ & $4,4(1,3)$ \\
\hline Mothers occupational status & $50,4^{*}(15,4) \$$ & $43,4^{*}(14,7) \$$ & $43,0(14,5)$ & $43,2(14,6)$ \\
\hline Mothers educational level & $4,8^{*}(1,3)$ & $4,4^{*}(1,4) \$$ & $4,3(1,3)$ & $4,3(1,3)$ \\
\hline Number of siblings & $1,5^{*}(1,1) \$$ & $1,8^{*}(1,3)$ & $1,8(1,3)$ & $1,8(1,3)$ \\
\hline Parental academic interest & $0,41^{*}(0,90)$ & $-0,09^{*}(1,01) \$$ & $0,02(0,95)$ & $0,01(0,97)$ \\
\hline Family cultural possessions & $0,46^{*}(0,89) \$$ & $-0,12^{*}(1,00) \$$ & $-0,03(0,99)$ & $-0,03(0,99)$ \\
\hline Family wealth & $0,55^{*}(0,93)$ & $0,03^{*}(0,82) \$$ & $-0,02(0,95)$ & $0,00(0,94)$ \\
\hline Single parent family & $0,15(0,35) \$$ & $0,12(0,33) \$$ & $0,16(0,37)$ & $0,15(0,36)$ \\
\hline Other family form & $0,07(0,26) \$$ & $0,08(0,27) \$$ & $0,10(0,30)$ & $0,09(0,29)$ \\
\hline $\begin{array}{l}\text { Average Fathers occupational } \\
\text { status }\end{array}$ & $53,9^{*}(8,3) \$$ & $45,9^{*}(7,4) \$$ & $43,6(7,0)$ & $44,3(7,3)$ \\
\hline Average Family wealth & $0,55^{*}(0,48) \$$ & $0,03^{*}(0,40) \$$ & $-0,02(0,57)$ & $0,00(0,55)$ \\
\hline $\begin{array}{l}\text { Average Family cultural } \\
\text { possessions }\end{array}$ & $0,46^{*}(0,42)$ & $-0,12^{*}(0,47) \$$ & $-0,04(0,44)$ & $-0,04(0,45)$ \\
\hline School size: number of pupils & $666^{*}(357) \$$ & $712^{*}(420) \$$ & $694(435)$ & $696(431)$ \\
\hline Hours of schooling per year & $983,9^{*}(151,1) \$$ & $991,1^{*}(109,1) \$$ & $943,4(138,6)$ & $952,1(136,0)$ \\
\hline Pupil/teacher ratio. & $13,4^{*}(4,5) \$$ & $13,3^{*}(4,3) \$$ & $12,8(4,7)$ & $12,9(4,6)$ \\
\hline School instructional resources & $-0,73^{*}(0,87)$ & $-0,24^{*}(0,96)$ & $-0,08(0,96)$ & $-0,13(0,97)$ \\
\hline Teachers' misbehavior & $-0,84^{*}(0,96) \$$ & $-0,13^{*}(1,00) \$$ & $-0,01(0,9)$ & $-0,05(0,93)$ \\
\hline Pupils' misbehavior & $-0,88^{*}(0,96) \$$ & $-0,29^{*}(1,04) \$$ & $0,04(0,89)$ & $-0,04(0,93)$ \\
\hline Teacher morale & $0,39^{*}(1,03) \$$ & $0,06^{*}(0,89) \$$ & $-0,08(0,95)$ & $-0,05(0,95)$ \\
\hline
\end{tabular}

* Significant differences between the averages are compared with that of public schools $(t$-test with unequal variances; $p<0,05$ ); $\$$ significant differences in standard deviation compared with those of public schools Levene's test; $p<0,05)$. Source: PISA survey, 2000. 


\section{Table 2a: Coefficients of five hierarchical multilevel-models with the mathematical score as dependent variable (standard error between parentheses)}

\begin{tabular}{|c|c|c|c|c|c|}
\hline Model & 1 & 2 & 3 & 4 & 5 \\
\hline Constant & $281,91(19,38)$ & $296,59(19,38)$ & $219,77(20,11)$ & $208,07(20,78)$ & $224,59(20,71)$ \\
\hline Private independent & $23,10(4,36)$ & $24,25(4,61)$ & $-8,69(4,20)$ & $-8,57(4,22)$ & $-10,66(4,11)$ \\
\hline Private dependent & $11,14(2,54)$ & $10,99(2,54)$ & $2,64(2,21)$ & $2,58(2,21)$ & $0,51(2,15)$ \\
\hline Public & ref. & ref. & ref. & ref. & ref. \\
\hline Age & $-0,94(0,10)$ & $-0,95(0,10)$ & $-0,91(0,10)$ & $-0,91(0,10)$ & $-0,91(0,10)$ \\
\hline Grade & $36,25(0,74)$ & $36,24(0,74)$ & $35,12(0,73)$ & $35,03(0,73)$ & $34,91(0,73)$ \\
\hline Male & $-15,17(0,70)$ & $15,20(0,70)$ & $15,79(0,71)$ & $15,55(0,70)$ & $15,56(0,70)$ \\
\hline Mothers' occupational status & $0,33(0,03)$ & $0,33(0,03)$ & $0,31(0,03)$ & $0,31(0,03)$ & $0,30(0,03)$ \\
\hline Fathers 'occupational status & $0,32(0,03)$ & $0,37(0,03)$ & $0,28(0,03)$ & $0,28(0,03)$ & $0,28(0,03)$ \\
\hline Mothers' education & $2,48(0,32)$ & $2,50(0,32)$ & $2,26(0,32)$ & $2,24(0,32)$ & $2,20(0,32)$ \\
\hline Fathers' education & $1,64(0,32)$ & $0,17(0,32)$ & $1,44(0,32)$ & $1,43(0,32)$ & $1,41(0,32)$ \\
\hline Number of sibling & $-2,22(0,27)$ & $-2,18(0,27)$ & $-1,98(0,27)$ & $-1,94(0,27)$ & $-1,92(0,27)$ \\
\hline Family wealth & $0,60(0,43)$ & $0,58(0,43)$ & $-0,08(0,44)$ & $-0,09(0,44)$ & $-0,07(0,44)$ \\
\hline Parental academic interest & $4,43(0,37)$ & $4,42(0,37)$ & $4,19(0,36)$ & $4,16(0,36)$ & $4,18(0,36)$ \\
\hline Family cultural possessions & $4,74(0,38)$ & $5,01(0,42)$ & $4,12(0,42)$ & $4,06(0,42)$ & $4,10(0,42)$ \\
\hline Single parent family & $-7,30(0,92)$ & $-7,36(0,92)$ & $-7,65(0,92)$ & $-7,56(0,92)$ & $-7,43(0,92)$ \\
\hline Other family form & $-8,78(1,13)$ & $8,81(1,13)$ & $-8,83(1,13)$ & $-8,79(1,13)$ & $-8,13(1,13)$ \\
\hline Nuclear family & ref. & ref. & ref. & ref. & ref. \\
\hline Private indep.*Occupation father & & $-0,38(0,13)$ & $-0,39(0,13)$ & $-0,40(0,13)$ & $-0,42(0,13)$ \\
\hline Private dep.* Occupation flater & & $-0,04(0,06)$ & $-0,04(0,06)$ & $-0,04(0,06)$ & $-0,04(0,06)$ \\
\hline Private indep. ${ }^{*}$ Cultural possessions & & $4,81(2,44)$ & $3,69(2,42)$ & $3,53(2,41)$ & $3,33(2,41)$ \\
\hline Private dep.* Cultural possessions & & $-2,25(0,97)$ & $-2,47(0,97)$ & $-2,48(0,96)$ & $-2,64(0,96)$ \\
\hline Average occupational status father & & & $1,61(0,12)$ & $1,55(0,12)$ & $1,37(0,12)$ \\
\hline Average family wealth & & & $11,49(2,21)$ & $11,25(2,20)$ & $9,78(2,15)$ \\
\hline Average cultural possession & & & $23,60(2,08)$ & $23,86(2,06)$ & $20,21(2,02)$ \\
\hline Town $>1.000000$ & & & ref. & ref. & ref. \\
\hline Town $>15.000$ & & & $12,43(2,10)$ & $12,91(2,08)$ & $11,28(2,02)$ \\
\hline Village & & & $19,41(2,26)$ & $20,30(2,26)$ & $17,25(2,21)$ \\
\hline$\%$ girl & & & $0,62(3,20)$ & $1,79(3,17)$ & $-0,91(3,09)$ \\
\hline Learning time mathematics & & & & $0,06(0,01)$ & $0,06(0,01)$ \\
\hline School size*100 & & & & $0,4(0,2)$ & $0,5(0,2)$ \\
\hline Hours of schooling per year* 100 & & & & $0,5(0,5)$ & $0,4(0,5)$ \\
\hline Pupil/teacher ratio & & & & $-0,38(0,16)$ & $-0,53(0,16)$ \\
\hline Instructional resources & & & & $-1,89(0,65)$ & $-0,57(0,66)$ \\
\hline Misbehavior teachers & & & & & $3,65(0,84)$ \\
\hline Misbehavior pupils & & & & & $-10,64(0,83)$ \\
\hline Morale teachers & & & & & $1,48(0,72)$ \\
\hline Variances individual & $2493,40(29,05)$ & $2451,75(30,37)$ & $2446,66(30,28)$ & $2438,35(30,22)$ & $2439,43(30,21)$ \\
\hline Variances school & $1034,03(35,51)$ & $1024,37(35,48)$ & $691,82(26,43)$ & $675,80(25,97)$ & $615,61(24,33)$ \\
\hline Variances country & $806,43(264,90)$ & $805,63(264,50)$ & $755,02(247,24)$ & $823,75(269,55)$ & $821,72(268,82)$ \\
\hline Variances occ. father school level & & $0,12(0,04)$ & $0,12(0,04)$ & $0,11(0,04)$ & $0,10(0,04)$ \\
\hline Variances cult. poss. school level & & $13,82(9,13)$ & $14,83(9,03)$ & $14,21(8,99)$ & $14,64(8,97)$ \\
\hline$-2 * \log$ likelihood & 497173,3 & 497111 & 496247 & 496113 & 495936 \\
\hline
\end{tabular}




\section{Table 2b: Coefficients of five hierarchical multilevel-models with the reading score as dependent variable (standard error between parentheses)}

\begin{tabular}{|c|c|c|c|c|c|}
\hline Model & 1 & 2 & 3 & 4 & 5 \\
\hline Constant & $276,68(20,26)$ & $269,86(20,22)$ & $185,09(21,08)$ & $180,64(21,90)$ & $199,39(21,86)$ \\
\hline Private independent & $28,56(5,04)$ & $28,52(5,19)$ & $-11,26(4,63)$ & $-12,17(4,67)$ & $-14,65(4,55)$ \\
\hline Private dependent & $15,21(2,93)$ & $15,03(2,93)$ & $4,46(2,50)$ & $4,70(2,52)$ & $2,25(2,83)$ \\
\hline Public & ref & ref. & ref. & ref & ref. \\
\hline Age & $-0,97(0,11)$ & $-0,97(0,11)$ & $-0,94(0,11)$ & $-0,94(0,11)$ & $-0,94(0,11)$ \\
\hline Grade & $42,08(0,77)$ & $42,04(0,77)$ & $40,88(0,76)$ & $40,83(0,76)$ & $40,74(0,75)$ \\
\hline Male & $-21,39(0,74)$ & $-21,43(0,74)$ & $-20,48(0,74)$ & $-20,48(0,74)$ & $-20,47(0,74)$ \\
\hline Mothers' occupational status & $0,33(0,03)$ & $0,33(0,03)$ & $0,30(0,03)$ & $0,30(0,03)$ & $0,30(0,03)$ \\
\hline Fathers 'occupational status & $0,46(0,03)$ & $0,46(0,03)$ & $0,38(0,03)$ & $0,38(0,03)$ & $0,39(0,03)$ \\
\hline Mothers' education & $2,79(0,33)$ & $2,79(0,33)$ & $2,56(0,33)$ & $2,56(0,33)$ & $2,52(0,33)$ \\
\hline Fathers' education & $1,13(0,34)$ & $1,14(0,34)$ & $0,92(0,33)$ & $0,92(0,33)$ & $0,91(0,33)$ \\
\hline Number of sibling & $-4,03(0,28)$ & $-4,28(0,33)$ & $-4,04(0,33)$ & $-4,04(0,33)$ & $-4,04(0,33)$ \\
\hline Family wealth & $-2,45(0,46)$ & $-2,47(0,46)$ & $-3,07(0,46)$ & $-3,07(0,46)$ & $-3,05(0,46)$ \\
\hline Parental academic interest & $8,68(0,38)$ & $8,71(0,38)$ & $8,47(0,38)$ & $8,46(0,38)$ & $8,47(0,38)$ \\
\hline Family cultural possessions & $7,20(0,40)$ & $7,50(0,45)$ & $6,60(0,45)$ & $6,59(0,45)$ & $6,64(0,45)$ \\
\hline Single parent family & $-8,73(0,97)$ & $-8,68(0,97)$ & $-9,07(0,96)$ & $-9,05(0,96)$ & $-8,91(0,96)$ \\
\hline Other family form & $-8,36(1,19)$ & $-8,42(1,19)$ & $-8,51(1,19)$ & $-8,49(1,19)$ & $-8,33(1,19)$ \\
\hline Nuclear family & ref. & ref. & ref & ref. & ref. \\
\hline Private indep.*Number siblings & & $6,06(1,97)$ & $5,72(1,96)$ & $5,69(1,96)$ & $5,52(1,95)$ \\
\hline Private dep.*Number siblings & & $1,24(0,81)$ & $1,02(0,81)$ & $1,03(0,81)$ & $1,13(0,81)$ \\
\hline Private indep. ${ }^{*}$ Cultural possessions & & $2,38(2,61)$ & $1,35(2,58)$ & $1,26(2,58)$ & $1,05(2,57)$ \\
\hline Private dep.* Cultural possessions & & $-2,43(1,04)$ & $-2,69(1,03)$ & $-2,69(1,03)$ & $-2,86(1,03)$ \\
\hline Average occupational status father & & & $1,79(0,14)$ & $1,78(0,14)$ & $1,56(0,14)$ \\
\hline Average family wealth & & & $11,82(2,49)$ & $11,43(2,49)$ & $9,75(2,43)$ \\
\hline Average cultural possession & & & $30,92(2,35)$ & $31,00(2,35)$ & $26,90(2,30)$ \\
\hline Town $>1.000000$ & & & Ref. & ref. & ref. \\
\hline Town $>15.000$ & & & $12,15(2,38)$ & $12,63(2,37)$ & $10,81(2,31)$ \\
\hline Village & & & $17,61(2,56)$ & $18,60(2,58)$ & $15,19(2,52)$ \\
\hline$\%$ girl & & & $12,05(3,62)$ & $11,98(3,61)$ & $8,79(3,51)$ \\
\hline Learning time reading & & & & $0,01(0,01)$ & $0,01(0,01)$ \\
\hline School size*100 & & & & $0,3(0,2)$ & $0,4(0,2)$ \\
\hline Hours of schooling per year* 100 & & & & $0,6(0,5)$ & $0,5(0,5)$ \\
\hline Pupil/teacher ratio & & & & $-0,38(0,18)$ & $-0,57(0,18)$ \\
\hline Instructional resources & & & & $-2,83(0,74)$ & $-1,27(0,75)$ \\
\hline Misbehavior teachers & & & & & $3,88(0,96)$ \\
\hline Misbehavior pupils & & & & & $-11,96(0,94)$ \\
\hline Morale teachers & & & & & $1,73(0,82)$ \\
\hline Variances individual & $3638,45(32,61)$ & $3586,27(33,96)$ & $3580,49(33,88)$ & $3580,01(33,88)$ & $3579,63(33,86)$ \\
\hline Variances school & $1439,63(47,33)$ & $1429,15(47,29)$ & $935,52(33,85)$ & $924,62(33,56)$ & $848,44(31,49)$ \\
\hline Variances country & $721,55(238,44)$ & $713,10(235,58)$ & $637,88(210,10)$ & $675,53(222,15)$ & $710,97(233,41)$ \\
\hline Variances occ. father school level & & $16,49(5,51)$ & $16,76(5,46)$ & $16,87(5,46)$ & $16,74(5,44)$ \\
\hline Variances cult. poss. school level & & $32,88(10,33)$ & $30,94(10,14)$ & $30,82(10,13)$ & $30,53(10,10)$ \\
\hline$-2 * \log$ likelihood & 500554,60 & 500502,60 & 499545,60 & 499519,80 & 499345,70 \\
\hline
\end{tabular}


Table 3a: Random coefficients and their variances of social background characteristics; variances each separately estimated in model 1 with mathematical score as dependent variable (standard error between parenthesis)

\begin{tabular}{|l|l|l|}
\hline Variable & Fixed Coefficient & Variances \\
\hline Mothers occupational status & $0,34(0,03)$ & $0,07(0,04)$ \\
\hline Fathers occupational status & $0,35(0,03)$ & $0,15(0,04)$ \\
\hline Mothers education & $2,51(0,32)$ & $8,61(5,03)$ \\
\hline Fathers education & $1,67(0,33)$ & $11,89(5,01)$ \\
\hline Number of siblings & $-2,19(0,28)$ & $10,24(4,85)$ \\
\hline Family wealth & $0,67(0,44)$ & $25,81(11,22)$ \\
\hline Parental academic interest & $4,45(0,37)$ & $15,57(8,77)$ \\
\hline Family cultural possession & $4,75(0,39)$ & $19,60(8,97)$ \\
\hline Single parent family & $-7,30(0,92)$ & $0,00(0,00)$ \\
\hline Other family form & $-9,04(1,17)$ & $184,42(78,81)$ \\
\hline
\end{tabular}

Table 3b: Random coefficients and their variances of social background characteristics; variances each separately estimated in model 1 with reading score as dependent variable (standard error between

\begin{tabular}{|l|l|l|}
\hline Variable & Fixed Coefficient & Variances \\
\hline Mothers occupational status & $0,33(0,03)$ & $0,11(0,04)$ \\
\hline Fathers occupational status & $0,48(0,03)$ & $0,10(0,04)$ \\
\hline Mothers education & $2,81(0,34)$ & $14,37(5,78)$ \\
\hline Fathers education & $1,17(0,34)$ & $13,24(5,58)$ \\
\hline Number of siblings & $-3,95(0,30)$ & $17,62(5,56)$ \\
\hline Family wealth & $-2,55(0,47)$ & $42,34(13,02)$ \\
\hline Parental academic interest & $8,81(0,42)$ & $66,11(11,21)$ \\
\hline Family cultural possession & $7,18(0,41)$ & $33,54(10,36)$ \\
\hline Single parent family & $-8,74(0,99)$ & $79,17(60,69)$ \\
\hline Other family form & $-8,65(1,27)$ & $385,30(93,90)$ \\
\hline
\end{tabular}




\section{Appendix}

Table A1a: Interaction-effects of social background characteristics with school type, estimated per social background variable in model 1 with mathematical score as dependent variable, with main effects and variances (standard error between parentheses)

\begin{tabular}{|l|l|l|}
\hline Variable & Coefficient & Variances \\
\hline Private independent & $41,07(8,51)$ & \\
\hline Private dependent & $14,09(3,86)$ & \\
\hline Occupational status father & $0,37(0,03)$ & $0,14(0,04)$ \\
\hline Private indep.* ${ }^{*}$ Occupation father & $-0,34(0,13)$ & \\
\hline Private dep.* Occupation father & $-0,07(0,06)$ & \\
\hline & & \\
\hline Private independent & $29,31(9,43)$ & \\
\hline Private dependent & $9,88(3,92)$ & \\
\hline Education father & $1,65(0,36)$ & $11,74(5,00)$ \\
\hline Private indep.* education father & $-1,27(1,72)$ & \\
\hline Private dep.* education father & $0,26(0,70)$ & \\
\hline & & \\
\hline Private independent & $19,59(5,16)$ & \\
\hline Private dependent & $9,33(2,86)$ & \\
\hline Number siblings & $-2,39(0,31)$ & $9,95(4,84)$ \\
\hline Private indep.*siblings & $2,11(1,82)$ & \\
\hline Private dep.* siblings & $0,91(0,76)$ & \\
\hline & & \\
\hline Private independent & $25,25(4,51)$ & \\
\hline Private dependent & $11,16(2,52)$ & \\
\hline Family wealth & $0,87(0,49)$ & $25,55(11,21)$ \\
\hline Private indep.* Wealth & $-3,61(2,38)$ & \\
\hline Private dep.* Wealth & $-0,55(1,17)$ & \\
\hline & & \\
\hline Private independent & $21,36(4,49)$ & \\
\hline Private dependent & $11,01(2,54)$ & \\
\hline Family Cultural possession & $5,07(0,42)$ & $18,35(8,93)$ \\
\hline Private indep.*Cultural poss. & $3,42(2,43)$ & \\
\hline Private dep.*Cultural poss. & $-2,39(0,10)$ & \\
\hline & & \\
\hline Private independent & $23,40(4,43)$ & \\
\hline Private dependent & $10,70(2,57)$ & \\
\hline Other family form & $-9,62(1,27)$ & $175,92(78,47)$ \\
\hline Private indep.*Other & $-4,21(7,89)$ & \\
\hline Private dep.*Other & $4,89(3,35)$ & \\
\hline
\end{tabular}


Table A1b: Interaction-effects of social background characteristics with school type, estimated per social background variable in model 1 with reading as dependent variable, with main effects and variances (standard error between parentheses)

\begin{tabular}{|l|l|l|}
\hline Variable & Coefficient & Variances \\
\hline Private independent & $35,80(9,04)$ & \\
\hline Private dependent & $12,95(4,20)$ & \\
\hline Occupational status mother & $0,33(0,03)$ & $0,11(0,04)$ \\
\hline Private indep.*Occupation mother & $-0,15(0,15)$ & \\
\hline Private dep.* Occupation mother & $0,05(0,07)$ & \\
\hline & & \\
\hline Private independent & $41,96(9,33)$ & \\
\hline Private dependent & $18,89(4,26)$ & \\
\hline Occupational status father & $0,51(0,03)$ & $0,10(0,04)$ \\
\hline Private indep.*Occupation father & $-0,25(0,14)$ & \\
\hline Private dep.* Occupation father & $-0,08(0,06)$ & \\
\hline & & \\
\hline Private independent & $27,20(10,26)$ & \\
\hline Private dependent & $14,51(4,36)$ & \\
\hline Education father & $1,13(0,38)$ & $13,24(5,59)$ \\
\hline Private indep.* education father & $0,25(1,82)$ & \\
\hline Private dep.* education mother & $0,15(0,75)$ & \\
\hline & & \\
\hline Private independent & $36,91(10,04)$ & \\
\hline Private dependent & $21,35(4,40)$ & \\
\hline Education mother & $3,14(0,38)$ & $13,84(5,76)$ \\
\hline Private indep.* education mother & $-1,78(1,19)$ & \\
\hline Private dep.* education mother & $-1,44(0,76)$ & \\
\hline & & \\
\hline Private independent & $18,72(5,83)$ & \\
\hline Private dependent & $13,06(3,25)$ & \\
\hline Number siblings & $-4,28(0,33)$ & $16,22(5,51)$ \\
\hline Private indep.*siblings & $6,20(1,97)$ & \\
\hline Private dep.* siblings & $1,16(0,81)$ & \\
\hline & & \\
\hline Private independent & $27,09(5,16)$ & \\
\hline Private dependent & $7,49(0,45)$ & $32,53(10,33)$ \\
\hline Family wealth & $15,39(2,91)$ & \\
\hline Private indep.* Wealth & $-2,41(0,52)$ & $42,27(13,02)$ \\
\hline Private dep.* Wealth & $-0,68(2,62)$ & \\
\hline & $-0,85(1,26)$ & \\
\hline Private independent & & \\
\hline Private dependent & $27,38(5,14)$ & \\
\hline Parental academic interest & $15,04(2,94)$ & \\
\hline Private indep.* academic interest & $2,87(0,46)$ & $65,92(11,20)$ \\
\hline Private dep.*academic interest & $-0,73(1,07)$ & \\
\hline & & \\
\hline Private independent & & \\
\hline Frivate dependent & & \\
\hline
\end{tabular}




\begin{tabular}{|l|l|l|}
\hline Private indep. ${ }^{*}$ Cultural poss. & $2,82(2,61)$ & \\
\hline Private dep. ${ }^{\text {Cultural poss. }}$ & $-2,36(1,04)$ & \\
\hline & & \\
\hline Private independent & $28,69(5,13)$ & \\
\hline Private dependent & $14,94(2,96)$ & \\
\hline Other family form & $-8,86(1,38)$ & $384,33(93,86)$ \\
\hline Private indep.*Other & $-0,63(8,57)$ & \\
\hline Private dep.*Other & $1,67(3,66)$ & \\
\hline
\end{tabular}

Table A2: Additional analyses with interaction effects of social background characteristics variables with the averages of these characteristics at the school level, for both dependent variables

\begin{tabular}{|l|l|l|}
\hline Model & 6 (Mathematics) & 6 (Reading) \\
\hline Constant & $224,61(20,71)$ & $210,55(21,95)$ \\
\hline Private independent & $-10,72(4,11)$ & $-14,824(4,53)$ \\
\hline Private dependent & $0,517(2,15)$ & $2,24(2,43)$ \\
\hline Public & ref. & ref. \\
\hline Age & $-0,91(0,102)$ & $-0,94(0,11)$ \\
\hline Grade & $34,92(0,726)$ & $40,73(0,74)$ \\
\hline Male & $15,56(0,70)$ & $-20,42(0,74)$ \\
\hline Mothers' occupational status & $0,30(0,03)$ & $0,30(0,03)$ \\
\hline Fathers 'occupational status & $0,28(0,150$ & $0,387(0,03)$ \\
\hline Mothers' education & $2,21(0,32)$ & $2,52(0,33)$ \\
\hline Fathers' education & $1,41(0,32)$ & $0,90(0,33)$ \\
\hline Number of sibling & $-1,92(0,27)$ & $0,85(0,93)$ \\
\hline Family wealth & $-0,06(0,437)$ & $-3,06(0,46)$ \\
\hline Parental academic interest & $4,18(0,363)$ & $8,49(0,38)$ \\
\hline Family cultural possessions & $3,97(0,43)$ & $6,47(0,45)$ \\
\hline Single parent family & $-7,43(0,92)$ & $-8,89(0,96)$ \\
\hline Other family form & $-8,65(1,13)$ & $-8,42(1,19)$ \\
\hline Nuclear family & ref. & ref. \\
\hline Private indep.*occupation father & $-0,41(0,13)$ & \\
\hline Private dep.*occupation father & $-0,04(0,061$ & \\
\hline Private indep.*Cultural poss. & $3,96(2,43)$ & $1,83(2,60)$ \\
\hline Private dep.* Cultural poss. & $-2,74(0,97)$ & $-3,00(1,03)$ \\
\hline Private indep.*siblings & & $4,67(1,96)$ \\
\hline Private dep.*siblings & & $1,25(0,80)$ \\
\hline Average cultural poss. ${ }^{*}$ Cultural & $-1,57(0,86)$ & $-1,92(0,93)$ \\
\hline poss. & $0,00(0,00)$ & \\
\hline Average Occ. father* occ. father & & $-2,35(0,42)$ \\
\hline Average siblings* siblings & ref. & ref. \\
\hline Average occupational status father & $1,38(0,12)$ & $1,51(0,14)$ \\
\hline Average family wealth & $9,80(2,15)$ & $8,70(2,43)$ \\
\hline Average cultural possession & $20,03(2,02)$ & $27,07(2,29)$ \\
\hline Town >1.000000 & & \\
\hline
\end{tabular}




\begin{tabular}{|l|l|l|}
\hline Town $>15.000$ & $11,19(2,02)$ & $10,69(2,30)$ \\
\hline Village & $17,13(2,20)$ & $15,32(2,50)$ \\
\hline \% girl & $-0,84(3,09)$ & $9,09(3,49)$ \\
\hline Learning time & $0,06(0,006)$ & $0,01(0,006)$ \\
\hline School size*100 & $0,5(0,2)$ & $0,3(0,2)$ \\
\hline Hours of schooling per year*100 & $0,4(0,5)$ & $0,5(0,5)$ \\
\hline Pupil/teacher ratio & $-0,53(0,16)$ & $-0,56(0,18)$ \\
\hline Instructional resources & $-0,57(0,66)$ & $-1,22(0,75)$ \\
\hline Misbehavior teachers & $3,65(0,84)$ & $3,89(0,95)$ \\
\hline Misbehavior pupils & $-10,64(0,83)$ & $-11,74(0,94)$ \\
\hline Morale teachers & $1,49(0,72)$ & $1,81(0,81)$ \\
\hline Variances individual & $2439,43(30,21)$ & 3580,17 \\
\hline Variances school & $614,32(24,29)$ & $836,09(31,14)$ \\
\hline Variances country & $818,22(267,61)$ & $734,77(241,161)$ \\
\hline $\begin{array}{l}\text { Variances occ. father at school } \\
\text { level }\end{array}$ & $0,10(0,04)$ & \\
\hline $\begin{array}{l}\text { Variances cultural poss. at school } \\
\text { level }\end{array}$ & $14,78(8,98)$ & $16,00(5,40)$ \\
\hline Variances siblings at school level & & $30,10(10,08)$ \\
\hline$-2 *$ log likelihood & 495933 & 499310 \\
\hline & & \\
\hline
\end{tabular}

\section{Notes}

\footnotetext{
${ }^{1}$ Direct all correspondence to the second author: European University Institute, Via dei Roccettini, 9. 50016 San Domenico di Fiesole, Italy. E-mail: jaap.dronkers@,iue.it.The address of the first author is: Department of Sociology, University of Utrecht, Heidelberglaan 2, 3584 CS, Utrecht, the Netherlands. E-mail: r.corten@fss.uu.nl.

www.pisa.oecd.org/pisa/

3 In fact, age is taken as a serious explanatory variable for pupils' performance even if the grade of the target population was defined in a narrow way (15 years old). This is why a very precise measure of age in month is applied in the data, and only a three-month testing window was allowed for the data collection in the countries in order to ensure the accuracy of pupils' age at the time of assessment.
} 